\title{
"Salir del closet de la blanquitud": experiencias racializadas de practicantes de candombe afrouruguayo en el Litoral argentino
}

Julia Broguet ${ }^{1}$

\section{Resumen}

El presente trabajo se inscribe en una investigación doctoral más amplia que examinó cómo la expansión de una manifestación cultural considerada "negra" -el candombe afrouruguayo- en tres ciudades del Litoral argentino -Paraná, Santa Fe y Rosario- comprendió un creciente cuestionamiento de la construcción de blanquitud del contexto social y cultural al cual arribó. En esta ocasión nos proponemos exponer los replanteos identitarios que generó el encuentro con el candombe afrouruguayo entre sus practicantes locales, en particular cómo este proceso de construcción social de la blanquitud se inscribió en su cotidiano, describir las dificultades para adecuarse a tal ideal y el desafío y la transformación que representó la incorporación del candombe en sus vidas. A tal fin señalamos el papel de nociones como "comunidad" y "filiación" en los interrogantes formulados por las agrupaciones locales y los sentidos étnico-raciales/espaciales específicos que adquieren en el contexto estudiado. De este modo describimos sus cuestionamientos a la persistente marginación de las procedencias mestizas/afromestizas/negras de sus memorias familiares pero también de la historia en común con la que se identifican al reconocerse "argentinos/as".

\section{Palabras claves}

Candombe afrouruguayo. Litoral argentino. Blanquitud.

\section{Introducción}

El presente trabajo se inscribe en una investigación doctoral más amplia en la que examiné cómo la expansión de una manifestación cultural considerada "negra" -el candombe afrouruguayo- en tres ciudades argentinas -Paraná, Santa Fe y Rosario- comprendió un creciente cuestionamiento de la construcción de blanquitud del contexto social y cultural al cual arribó

1 Doutora em Antropologia na Universidad de Buenos Aires (UBA). E-mail: juliabroguet@gmail.com. 
(BROGUET, 2020)2 ${ }^{2}$ En esta ocasión me propongo exponer los replanteos identitarios que generó el encuentro con el candombe afrouruguayo entre sus practicantes locales, en particular cómo experimentan los procesos de racialización involucrados en la narrativa nacional argentina.

Aunque en Argentina el sentido común dice que "no hay negros" y, en consecuencia, "no hay racismo", el funcionamiento local de formas de categorización racial se asocia a sentidos desvalorizados, negativos, estereotipantes y/o exotizantes de la negritud que, como iremos viendo a lo largo del trabajo, no afectan sólo a la población afrodescendiente ${ }^{3}$. El hecho de que las categorías de negritud circulantes en nuestro contexto sean poco cuestionadas y el problema del racismo prácticamente no se nombre, no le resta existencia. En tal sentido, la raza es un elemento "ocluido" en la comprensión de la desigualdad social argentina (FRIGERIO, 2006). Asimismo, hay quienes subrayan que la definición del ser nacional se concibió desde una europeitud/blanquitud genérica (BRIONES, 2008, p. 21), que obstaculizó el reconocimiento de los procesos de etnización/racialización en los que se vio envuelto. En términos generales, al referirnos a los replanteos en las identificaciones étnico-raciales de las y los practicantes locales aludimos a los modos en que, a partir de la práctica del candombe afrouruguayo, revisan y cuestionan el europeísmo -y el blanqueamiento asociado a esta amplia procedencia étnica- como tropo definitorio y excluyente de lo argentino.

El candombe es una manifestación que surge durante el período colonial en el Río de la Plata como una mixtura de elementos culturales de grupos étnicos africanos trasladados forzosamente a América mediante el tráfico esclavista. Designa un espacio sociocultural y una práctica comunitaria (UNESCO, 2009) en la que se entraman dimensiones estético-expresivas (música, danza, cantos) así como identitarias, históricas, políticas y económicas. Pese a que el término es homólogo de uno y otro lado del Plata, faltan estudios que permitan identificar singularidades en los desarrollos específicos que esta manifestación

\footnotetext{
2 El uso que hacemos del entrecomillado es para señalar términos y/o expresiones del propio campo. Cuando los registros excedan palabras o expresiones breves, citaremos la referencia completa (persona, fecha y lugar). Los nombres que empleamos para nombrar a nuestras/os interlocutoras/es son ficticios.

${ }^{3}$ En el año 2010 se incorporó por primera vez una pregunta sobre afrodescendencia en el Censo Nacional de Población, Hogares y Viviendas. Según este cesno 149.493 personas se reconocen como "afrodescendientes" en Argentina, lo cual representa un 0,4\% de la población total. Por cuestiones de espacio no es posible detallar las dificultades en la implementación y la diferencia de resultados respecto a las estimaciones que hacían las organizaciones afrodescendientes locales. Actualmente se discute la instrumentación de una pregunta sobre afrodescendencia en el próximo censo, que estaba planificado para el año 2020 pero se aplazó por la pandemia COVID-19.
} 
tuvo a partir de la consolidación de los procesos nacionales hacia fines del siglo XIX. No obstante, diferentes investigaciones coinciden que hacia fines de este periodo, se produce un repliegue del candombe en Buenos Aires hacia espacios privados por los cuales transitaban casi exclusivamente familias afroargentinas (FRIGERIO, 2000); mientras que en Montevideo, para el mismo período, esta práctica gana crecientemente el espacio público y se expande entre sectores sociales no-negros hasta convertirse en un "ritmo nacional" (ANDREWS, $2007)^{4}$. Es decir que si bien ambas naciones se constituyeron en torno a una ideología de blanqueamiento social, en Argentina su penetración y eficacia fue mayor que en Uruguay, debido al fuerte impulso integrador y homogeneizador que sostenía el Estado argentino (GELER, 2011).

Cabe aclarar que "afrouruguayo" no es una denominación del propio campo. Con este término me interesa subrayar por un lado, la dimensión nacional (ya que no abordo procesos vinculados al candombe en Uruguay sino a los derivados de su arribo a localidades argentinas) y; por otro, la dimensión étnico-racial vinculada al prefijo "afro". Esto último no excluye otras procedencias étnico-raciales que hicieron al candombe tal como lo conocemos hoy. Tampoco significa que "ser afrouruguaya/o" equivalga a "hacer candombe". Pero sí que en el proceso de expansión de esta manifestación hacia ciudades argentinas la procedencia étnico-racial fue más enfatizada que la nacional. Si bien este énfasis moviliza estereotipos y prejuicios raciales entre practicantes locales acerca de cómo son o qué hacen "los/las afrouruguayos/as", mi interés es entender el lugar que ocupó el candombe en sus procesos identitarios y cómo colaboró a problematizar los usos asiduamente acusatorios, desvalorizantes o insultantes (no así ni necesariamente algunos sentidos exotizantes $)^{5}$ del término "negro" en Argentina, cuyo epítome es la expresión de uso corriente "negro de mierda".

En este contexto nacional el término negro no refiere sólo a una afrodescendencia; también puede aludir a argentinas/os de piel oscura con diversos orígenes étnico-raciales y provenientes de sectores populares (FRIGERIO, 2006, GELER, 2016) ${ }^{6}$. Es así que según la circunstancia se usa para nombrar a descendientes de africanas/os como a argentinas/os "no lo

\footnotetext{
${ }^{4}$ Tomamos como referencia a las capitales nacionales de Argentina y Uruguay dado que allí existe mayor caudal de investigaciones sobre el tema.

${ }^{5}$ Vuelvo sobre estos sentido exotizantes de la negritud en los próximos apartados.

${ }^{6}$ También es frecuente el uso afectuoso del término, entre familiares o amistades entre quienes media un vínculo de confianza. Y no siempre ni necesariamente este apelativo refiere al aspecto físico de la persona hacia quien va dirigido.
} 
suficientemente blancas/os", estigmatizados por su color de piel, determinados rasgos faciales y, sobre todo, por cómo tales elementos se articulan a clasificaciones sociales (FRIGERIO, 2006). En este caso, "negro" es un término más cercano a "mestizo" y señala una "mezcla" donde prevalece lo afrodescendiente y lo indígena por sobre lo europeo (BROGUET, 2020)7. Al realizar una manifestación afroamericana, mis interlocutoras/es incluyen la afrodescendencia como parte de esa "mezcla" étnico-racial constitutiva de la argentinidad. Algo menos frecuente en otros espacios sociales, pues la idea de "desaparición" de esta población se impuso con efectividad (ANDREWS, 1989). Asimismo, la polisemia del término "negro" les permite jugar con estos diversos sentidos: superponerlos, diferenciarlos o permitirse ambigüedades según las circunstancias (BROGUET, 2021).

La estructura de este escrito es la siguiente. Primero, expongo algunas interpelaciones de conocimiento que fueron parte del proceso investigativo y fueron orientando algunas decisiones teórico-metodológicas. Luego, caracterizo las dinámicas de mestizaje y blanqueamiento (BRIONES, 2005) en las que se desenvuelven los replanteos identitarios entre practicantes y señalo el papel de las segmentaciones espaciales del territorio nacional en tales procesos. Continúo puntualizando el lugar de nociones como "comunidad" y "filiación" en la reproducción social del candombe afrouruguayo en Montevideo y cómo se trasladan a las agrupaciones locales en forma de interrogantes que incluyen aspectos de las corporalidades de sus integrantes (color de piel, tipo de pelo, rasgos faciales). Finalmente, profundizo en el relato familiar de una practicante para describir cómo a partir de su inmersión en esta manifestación problematiza episodios de su infancia y juventud en las que se entraman dimensiones étnico-raciales, sociales y sexo-genéricas. En las conclusiones observo cómo en el proceso de incorporación del candombe los sujetos junto a quienes trabajamos buscan hacer "propia" una presencia étnica y racial mestiza/afromestiza/negra que, hasta no hace mucho tiempo, fue persistentemente marginada de su relato familiar pero también, y más ampliamente, de la historia en común con la que se identifican al reconocerse "argentinos/as".

\footnotetext{
${ }^{7}$ Briones (2005, p.69) bserva que en Argentina, a diferencia de otras naciones latinoamericanas, el término mestizo/a fue construido como "categoría subvaluada, como marca estigmatizante" lejana al "tipo nacional", más cercano al componente indígena y/o afrodescendiente que al europeo.
} 


\section{Interpelaciones de conocimiento: señalamientos teórico- metodológicos}

"Salir del closet de la blanquitud" es la expresión que retomo en el título y que recupera una conversación con un interlocutor rosarino que tradujo así su experiencia de acercamiento al candombe. En ese momento me pareció provocativa porque trazaba un paralelo entre el proceso de autopercepción de identidades de género $u$ orientaciones sexuales disidentes que interpelan a la heteronorma y el hecho de que, a partir de su inmersión en una práctica racializada, situaba a la blanquitud como ideal normativo que reguló la construcción de una identidad nacional argentina. Una blanquitud que además se vio reforzada por el europeísmo como un modo de representación dominante de esa argentinidad (LINS RIBEIRO, 2002). Durante nuestra charla también agregó que "cuando se acercó al candombe, se dio cuenta de que no era blanco", refiriéndose a que ni su apariencia corporal ni sus comportamientos sociales respondían adecuadamente al ideal de blanquitud europea que permeó diferentes dimensiones del cotidiano nacional y que el candombe fue una experiencia práctica que colaboró con este descubrimiento pues le permitió revisar episodios personales en los que pudo ir reconociendo cómo primó ese ideal sobre prácticas, formas de expresarse y de hacer vinculadas a las categorías de negritud circulantes en Argentina. A partir de este y otros emergentes del propio campo el esfuerzo analítico se orientó a comprender cómo se inscribió este proceso de construcción social de la blanquitud en el cotidiano de las y los practicantes de candombe y a describir las dificultades para adecuarse a tal ideal, tanto como el desafío y la transformación que representó la incorporación del candombe en sus vidas en la medida en que permitió articular experiencias racializadas previas ${ }^{8}$. La tarea investigativa se volcó, por un lado, a interrogar a ese sector mayoritario de la sociedad nacional que logra/puede incluirse en la argentinidad/blanquitud y que de esa manera se instala como el "punto de referencia para hablar del otro" (MORENO FIGUEROA, 2010, p.67). Por otro, y más específicamente, a cómo el acercamiento a manifestaciones culturales categorizadas "negras" generó replanteos en los procesos identitarios de sus practicantes. De este modo busqué comprender cómo entre practicantes argentinas/os, la blanquitud y la

\footnotetext{
${ }^{8}$ Tal interrogante había comenzado a despuntar en etnografías previas (BROGUET, 2012).
} 
europeidad suelen aparecer como ideales "desfasados" de su experiencia cotidiana (BROGUET, 2020).

A tal fin, el referente empírico de esta investigación estuvo compuesto por integrantes de agrupaciones de candombe afrouruguayo nacidos entre mediados de 1970 y 1980, quienes iniciaron su práctica en cada ciudad9. Aunque pertenecen a sectores medios, esta amplia descripción de su pertenencia social presenta matices ligados a sus diferentes experiencias habitacionales ${ }^{10}$. Además, al menos en los inicios de la pesquisa, tales practicantes no reivindicaban ninguna identidad étnico-racial específica. Hago este señalamiento porque en la zona en la que investigamos hay practicantes vinculados al candombe que se reivindican políticamente "afrodescendientes". Aunque esos procesos reivindicativos sirvieron de contrapunto, no fueron el foco de la presente indagación.

El trabajo de campo abarcó el periodo 2002-2017 e incluyó tres ciudades: Paraná, Santa Fe y Rosario. Paraná es la capital de la provincia de Entre Ríos (que limita con Uruguay). Santa Fe y Rosario son ciudades de la provincia de Santa Fe, cuya capital es la ciudad homónima (ver mapa).

\footnotetext{
${ }^{9}$ Este dato etario es significativo porque buena parte de las y los practicantes con quienes trabajamos se aproximaron al candombe afrouruguayo entre fines de los años 90 y comienzos del 2000, durante un periodo dinámico en lo que refiere al activismo negro en Uruguay con la emergencia de la Organización Mundo Afro (OMA) como actor político. El contacto con estas formas de reivindicación de la negritud racial asociadas al candombe afrouruguayo resultó significativo por el contraste con la realidad argentina y el valor mayormente negativo vinculado a la negritud (BROGUET, 2020 y 2021).

${ }^{10}$ Ver Broguet (2021).
} 


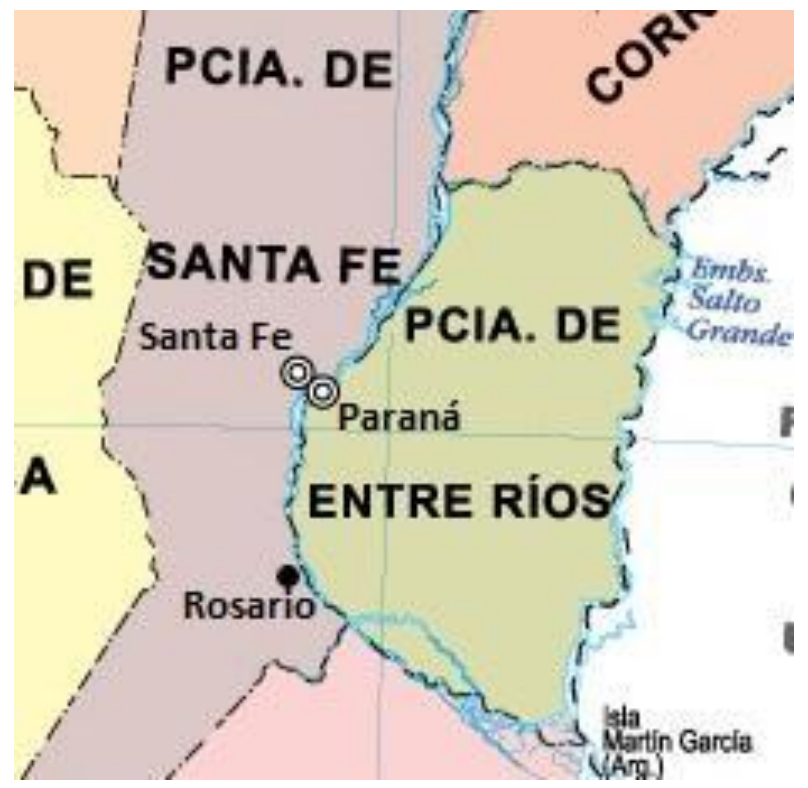

Fuente: Mapoteca.

El inicio del trabajo de campo se vincula con el propio acercamiento al campo en el año 2000 como practicante, y se extiende hasta el año 201711. En lo que refiere al tratamiento de las entrevistas, dialogan diferentes voces registradas en Paraná, Santa Fe y Rosario. Para exponer con mayor detalle los replanteos identitarios y las categorías étnico-raciales que movilizan, alterno esta dinámica con la estrategia de profundizar en relatos de practicantes que presentan un particular "carácter reflexivo y analítico-interpretativo" (MATO, 2002, p.30). Entiendo que tal carácter se nutre por un lado, de sus trayectorias universitarias en ciencias sociales -en general interrumpidas pero significativas- $\mathrm{y}$, por otro, de su contacto con organizaciones nacionales y extranjeras (artísticas, político-culturales, sociales) que sumaron nuevas

\footnotetext{
${ }^{11}$ Contamos con registros de observación que incluyen participaciones en eventos relacionados con el candombe, registros sobre el propio proceso de acercamiento al candombe y participaciones en proyectos de investigación, extensión universitaria y comunicación de la ciencia. Produjimos entrevistas, mayormente realizadas en el marco de la investigación doctoral y empleamos documentos de cada agrupación, materiales multimediales de redes sociales, extractos de testimonios y entrevistas en sitios webs y medios de comunicación -gráficos, televisivos y digitales- realizadas a practicantes de las tres ciudades. Finalmente, recurrimos a materiales surgidos de investigaciones previas sobre otras prácticas culturales afroamericanas en la zona.
} 
inquietudes y preocupaciones (político-culturales, sociales, identitarias) a la realización del candombe.

\section{"Miremos al interior. Nuestra Argentina es mayormente morocha": continuidades y superposiciones entre la interioridad provinciana y}

\section{familiar}

Las discusiones que retomamos sobre la categoría de raza en América Latina provienen mayormente de los estudios afrodescendientes (LAMBORGHINI, GELER Y GUZMAN, 2017) y rastrean cómo las identidades nacionales involucran identificaciones étnico-raciales que se materializan en corporalidades situadas, cambiantes y en desarrollo (WADE, 2013), así como en espacialidades constitutivas de esas corporalidades (RAHIER, 1999)12. Nuestro interés es identificar cómo tales dimensiones se ponen en juego en el acercamiento de practicantes locales a una manifestación cultural afroamericana donde se movilizan categorías étnico-raciales, de clase, región, sexo-genéricas que se desenvuelven entre diferentes escenarios nacionales (Uruguay y Argentina).

En contraste con otras naciones latinoamericanas, en Argentina, hay autoras/es que aluden a una "ceguera respecto de los procesos de mestizaje" (FRIGERIO, 2010) o a una "imposibilidad mestiza" (CORTI, 2010; GELER, 2016) a fin de señalar que no prima un modelo nacional que convierta "a la hibridación en capital simbólico del 'ser nacional'" (BRIONES, 2005, p.68). Por el contrario, advierten que se glorifica una "narrativa dominante de blanquitud" (FRIGERIO, 2010) que al recurrir a la imagen de un "crisol de razas", excluye a "indios y negros" y aspira a la mezcla de "razas" blancas de inmigrantes europeos (CORTI, 2010, p.5) restringiendo el acceso a la ciudadanía "al abandono de cualquier tipo de reivindicación étnico-racial por fuera de la etnicidad 'nacional’” (LAMBORGHINI, GELER y GUZMÁN, 2017, p.70).

Sin negar el carácter "homogeneizador" y los procesos de blanqueamiento que involucran las políticas de mestizaje defendidas por las elites latinoamericanas de países como México, Colombia o Brasil entre finales de siglo XIX y comienzos del XX, perspectivas más recientes vienen resaltando la

12 También retomamos investigaciones que abordan la dimensión racial en migraciones y pueblos originarios de Argentina (BRIONES, 2005, 2008; CAGGIANO, 2007). 
necesidad de avanzar sobre comprensiones que consideren al mestizaje como una ideología y una práctica "que involucran ideas de raza y mezcla racial" (WADE, 2013, p.44) que comprendieron "procesos de racialización" y no exclusivamente de "homogeneización" (CUNIN, 2010, p.9). Desde este punto de vista y sin rechazar la presencia de una eficaz narrativa argentina de blanquitud, analizaré cómo las identificaciones étnico-raciales de las y los practicantes se replantean en términos de una dinámica de mestizaje y blanqueamiento (BRIONES, 2005). En principio, porque permite exponer que, pese a la "ceguera" o "imposibilidad" de reconocer los procesos de mestizaje/racialización en nuestro contexto, estos fueron parte efectiva de la formación de un sujeto nacional. No sólo en lo referido al debate nacional del cambio de siglo (XIX-XX) sobre el "mestizaje como una realidad inevitable" (NARI, 1999, p.351); sino también en cómo incidieron los procesos históricos de intercambio cultural y sexual entre poblaciones en la definición de una argentinidad "vergonzante" (BRIONES, 2008, p.28) vinculada al origen indígena y afrodescendiente.

En esta línea, durante la investigación observé que a partir de su inmersión en el candombe las y los practicantes revisitaban las propias genealogías familiares para señalar la "negritud" de figuras que consideraban "silenciadas". En diálogo con el rastreo de bibliografía específica, advertí que tales usos de la negritud en el espacio familiar eran más cercanos a la idea de una "mezcla". Este y otros términos similares ("mistura", "cruza") aparecieron con frecuencia entre mis interlocutores para indicar los intercambios culturales/sexuales entre poblaciones de con diferentes procedencias étnicas. Así, al señalar esta "mezcla" enfatizaban (y no blanqueaban) la heterogénea composición étnico-racial de la nación argentina. Por lo cual aquí ahondaré en los usos locales de la negritud como el resultante de "una mezcla" de lo europeo con componentes no-blancos (indígena, afrodescendiente y/o mestizo).

Además, dinamizar un juego entre ambos términos (mestizaje y blanqueamiento) permite indagar en los modos desiguales en que esta ideología racial incidió a lo largo del territorio sobre el cual Argentina se constituyó como nación. Investigadoras/es locales advierten que la narrativa de blanquitud gestada en Buenos Aires, se extiende al resto del país y funciona como referencia de la nación en su conjunto (BRIONES, 2005; FRIGERIO, 2006). Pero como veremos, tal dinámica no transforma la fisura capital porteña/interior provinciano que es constitutiva de este espacio nacional, 
según la cual la presencia mestiza de provincias argentinas hace peligrar la blanquitud capitalina.

Los replanteos entre practicantes se vieron favorecidos por el contexto de las celebraciones del Bicentenario del 2010, incluidas en un proyecto político nacional más amplio que "reivindicaba -de formas desiguales y diversas- una patria más inclusiva y 'mestiza'" (LAMBORGHINI, GELER y GUZMÁN, 2017). En este escenario propicio para la inclusión de colectivos por largo tiempo expulsados de la consideración de la argentinidad, sitúo la convocatoria de Horacio, un practicante santafesino, a "mirar al interior". Tal llamado resultó sugerente para comprender el interés de varias/os interlocutores por inscribir espacialmente la composición étnico-racial del país. Sus lecturas racializadas del espacio nacional develan cuanto las categorizaciones étnico-raciales se entraman con segmentaciones y jerarquizaciones del espacio comprendido, en este caso, por la nación (BRIONES, 2008). Según la comprensión de Horacio, es en el "interior" (tal como suele denominarse al conjunto de las provincias argentinas) donde se encuentra la "Argentina moroch $a^{\text {"13 }}$ que fuerza a examinar la imagen de una "Argentina blanca" de la cual Buenos Aires es su mejor exponente:

Chaco, provincia criolla como Santa Fe, como Corrientes, Misiones, Formosa. A veces cuando se piensa en la Argentina, se piensa mucho en la Argentina blanca. Pero siempre digo, miremos el interior, porque creo que nuestra Argentina es mayormente morocha (Horacio, practicante, Santa Fe, 2017. Subrayado propio).

Horacio exhorta a "mirar" lo que fue poco (o nada) mirado en el marco de un ordenamiento espacial y racial con una cabeza muy visible representada por Buenos Aires y un cuerpo "grande y débil", interior y oculto, que subsume al resto de las provincias (BRIONES, 2008). Lo que, a grandes rasgos, confronta esta fragmentación espacial entre capital porteña/interior provinciano son "dos Argentinas"14. La co-existencia de dos configuraciones nacionales al interior de un mismo territorio encuentra su correlato en las corporalidades racializadas que habitan una y otra: las "blancas" y las "morochas". Así, el

\footnotetext{
${ }^{13}$ En el anteúltimo apartado caracterizamos los sentidos locales de esta categoría racializada.

14 Entendemos que esta segmentación espacial/étnico-racial es muy amplia y que pueden considerarse otros niveles contextuales (regional y urbano/barrial) en los que ésta se reproduce. Por cuestiones de espacio aquí no podremos desarrollar distintos niveles que abordamos en trabajos previos (BROGUET, 2020, 2021).
} 
extremo desvalorizado de la oposición planteada a nivel nacional (el "interior provinciano") se distancia del ideal normativo de blanquitud.

Siguiendo la metáfora espacial capital porteña/interior provinciano, los replanteos identitarios de las y los practicantes se trasladan al interior del espacio doméstico. De esta manera, se superponen a una serie de fragmentaciones, oposiciones y convergencias entre el afuera y el adentro, lo público y lo privado, la nación y la familia. No casualmente el silenciamiento de una parte de las genealogías familiares se vincula sobre todo a parientes que arriban como migrantes internos (o "cabecitas negras"15) a las ciudades cabeceras donde hoy habitan las y los practicantes; desde un "interior más interior" asociado a zonas del país que de acuerdo a esta segmentación espacial/racial son consideradas algunas de las más "oscuras" (BROGUET, 2020).

\section{Entre experiencias e inquietudes: comunidad y filiación en el candombe afrouruguayo}

Como adelanté, un punto recurrente en las conversaciones con practicantes es el referido a su "filiación" con una manifestación cultural aparentemente "ajena" en términos nacionales, étnicos y raciales, es decir, como "argentinas/os", "descendientes de europeas/os" y, como corolario de esta procedencia étnica, "blancas/os".

En su trabajo sobre las "llamadas"16 en Montevideo, Ferreira (1999 a y b) advierte la articulación entre nociones de "filiación" y "comunidad" en el candombe afrouruguayo y la centralidad de términos como familia, comunidad, ancestralidad, antepasados y parentesco en su historia y realización, donde se entraman con dimensiones étnico-raciales y habitacionales, asociadas al "barrio". En zonas de Montevideo con fuerte presencia afrouruguaya, "colgarse el tambor y formar" o "salir con los tambores" supone un saber hacer y una pertenencia grupal y sobre todo que "en tanto se toca, 'se es negro' y se es 'del barrio'" (FERREIRA, 1999b, p.9. Subrayado propio) ${ }^{17}$.

15 "Cabecita negra" es un término surgido en los años 40 que designaba al "inmigrante criollo y
mestizo que migraba desde el interior de la Nación para poblar el conurbano de "la" ciudad
capital, y en su confrontación chocaba con el racismo porteño" (FERNÁNDEZ BRAVO, 2014, p.16).
${ }^{16} \mathrm{El}$ "desfile de llamadas" es una celebración anual que se realiza en Montevideo durante el
periodo de carnaval.

${ }^{17}$ En este escrito nos detenemos fundamentalmente en el toque de tambores porque es el que ha 
A partir de los trabajos de este autor, Frigerio y Lamborghini (2011, p.111) observan que el toque de tambores también permite "crear comunidad" entre "porteños blancos de clase media" que desarrollan nuevas narrativas de pertenencia a fin de justificar la presencia del candombe afrouruguayo "más allá de del contingente inmigratorio uruguayo" presente en la ciudad. Aquí pretendo señalar que, entre practicantes del Litoral argentino la experiencia práctica de "comunidad" provoca una inquietud por la "filiación" que incluye un cuestionamiento sobre los propios "orígenes" étnico-raciales.

En escritos propios (BROGUET, PICECH y RODRÍGUEZ, 2014) indicamos que "hacer candombe" construye performativamente una comunidad de sentido entre practicantes locales que objeta el "modo de vida occidentalizado" y el "individualismo" que se le asocia. Así lo relataba una interlocutora:

El candombe generó una comunidad de gente que nos reunimos a vivir otras cosas de las que vivimos todos los días, buscamos un significado, que no es solamente la música: es encontrarse con el otro, compartir algo creativo y medio catártico (...) sacar algo que estás viviendo en tu vida también (Gilda, practicante, Paraná, 12/11).

Martín, practicante rosarino, sugiere que la experiencia de "comunidad" en el candombe resulta de una acción concreta como es el valor de "agregación" vinculado al toque de tambores ${ }^{18}$.

logrado un desarrollo más sostenido y especifico en el ámbito en las ciudades en las cuales trabajamos.

${ }^{18}$ Se trata de tres tambores (chico, piano y repique) que componen la formación básica para ejecutar el candombe afrouruguayo. 


\section{Carnavales en ciudad de Santa Fe.}

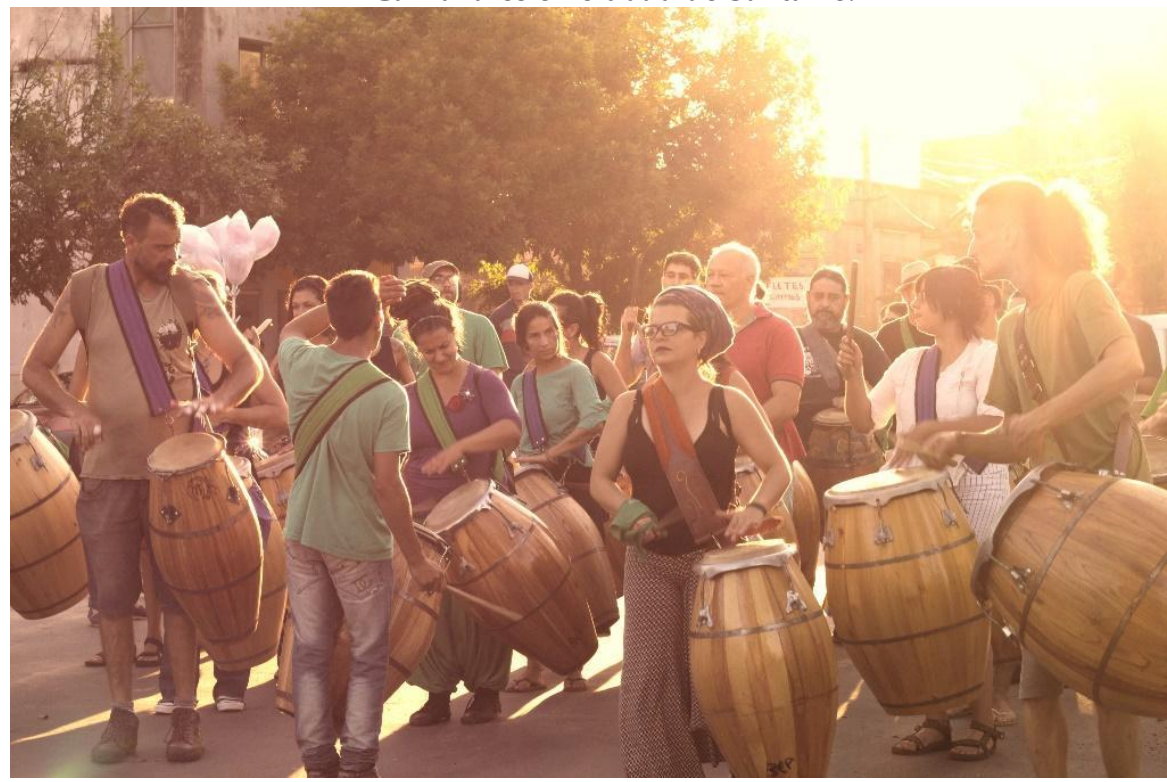

Fuente: https://elbirri.com/registro-colectivo-carnabarrial/

Es decir, la disposición a incorporar nuevos tambores a un conjunto que de esta manera aumenta su energía sonora. Lo cual produce una intensa "experiencia de conjunto", de "unidad que avanza con el sonido de los tambores" (Martín, practicante, Rosario, 03/15). Así indica que:

Hay momentos en el candombe donde uno siente ese efecto de comunidad (...) hay conversaciones que no están armadas desde la palabra, sino en la música, en los sonidos que hace cada tambor y eso genera una percepción en uno que es muy fuerte y enlaza todo el conjunto de tocadores (Martín, practicante, Rosario, 03/15).

Sin perder de vista las diferencias socio-históricas que caracterizan la "comunidad" de candomberas/os afromontevideanas/os de las que reúnen a practicantes argentinas/os, me interesa destacar el papel que tal noción juega en los procesos locales en torno al candombe, pues es a partir de esta experiencia práctica de "comunidad" que se instala la pregunta por la "filiación" en las agrupaciones. En un texto grupal una agrupación rosarina se interrogaba: 
Como candomberos, pero no-negros nos vemos llevados a pensar cuál es la filiación que podemos establecer con esta tradición em tanto que esa ligazón histórica para nosotros es apenas reciente y no implica el sedimento que sí se articula en aquellos que tocan "de familia" y pueden rememorar muchos años de historia en torno al candombe (Texto de la agrupación "Candombe Hormiga", Rosario, 11/12. Subrayado propio).

Uno de sus integrantes, indica que preguntarse por "lo que sucede acá" -en referencia a Argentina- viene de una "exigencia ética" que resume así: "si estas reivindicando una práctica cultural afrouruguaya, tenés que poner el ojo también en lo afro de acá" (Martín, practicante, Rosario, 03/15). "Lo afro de acá" rápidamente recae en la pregunta por su propia genealogía familiar. De este modo, la conversación lo lleva a una interpelación personal en torno a su "filiación", trazando un paralelo entre el sentido que le otorga un conocido referente del candombe en Uruguay y el que él mismo construye en relación con la suya:

Perico Goularte ${ }^{19}$ dice que en una llamada cada tocador tiene su antecesor, a su ancestro, cruzado de brazos, mirándolo. A uno no le pasa eso, evidentemente, porque mis antecesores me dirían (Imitando la voz de una persona de origen judío que habla español): “¿qué hacés querido? Cociná gefilte fish ${ }^{20 "}$ (Nos reímos). Igual uno siente, hay una noción de filiación que uno entiende. Entiende el recorrido histórico que pasó la comunidad afrouruguaya para llegar a consolidar esa expresión (Martín, practicante, Rosario, 03/15).

En ocasión de un taller de candombe afrouruguayo realizado en la Escuela de Música de la Universidad Nacional del Litoral en agosto de 2015, reapareció la inquietud de este practicante por la filiación, la pregunta por el hecho de ser considerados "blancos" y realizar una práctica "negra" y nuevos paralelos con su ascendencia judía. Su primera inquietud la expresa al decir que ya que "'el candombe es de los negros' 21 , la cuestión que se le presenta a una comparsa (...) es: ¿cómo establecer una filiación con una tradición que no nos pertenece?" (Registro escrito del taller, Rosario, 08/15. Subrayado propio). Por su parte a Ana, una practicante santafesina, el acercamiento al "candombe afrouruguayo" le

\footnotetext{
${ }^{19}$ Reconocido candombero afrouruguayo que integra el Grupo Asesor del Candombe (GAC).

${ }^{20}$ Se refiere a una comida de tradición judía

${ }^{21}$ La frase "el candombe es de los negros" que cita este practicante pertenece a una popular y antigua canción uruguaya del compositor Jacinto Piedrahita llamada "Candela", grabada por Alberto Castillo en 1959.
} 
permitió ir "descubriendo qué significa ser negro" y, sobre todo, cuestionar "la creencia generalizada de que los argentinos somos descendientes de europeos" (Ana, practicante, Santa Fe, 08/17). Recuerda que en un texto de difusión la presidenta de la Casa de la Cultura Indoafroamericana de Santa Fe -una organización afroargentina existente en el país desde 1988 y que actualmente preside Lucía Molina-, "escribió que tenemos muchas abuelas: abuelas blancas y europeas, pero también abuelas indígenas y abuelas negras". De este modo, indica que como sujetos nacionales estamos constituidos por una "mezcla" con estas abuelas históricamente menos "reconocidas", no solo en términos étnicos y raciales, sino por el hecho de ser mujeres. Como empezamos a observar, los procesos de racialización se materializan en corporalidades históricamente situadas y confieren un carácter vívido a las narrativas nacionales, donde se entrelazan "cultura y naturaleza, comportamiento y cuerpo, apariencia física y lo hereditario, color y sangre" (WADE, 2014, p.55).

\section{El lugar de la apariencia corporal en la pregunta por la filiación}

La inquietud por la filiación con el candombe envolvió la propia corporalidad de las y los practicantes. Muchas/os subrayan que la "mezcla" puede (o no) "ser visible" en la apariencia corporal. Cuando "no se ve", la propia "blanquitud/europeidad" expresa cierta incongruencia con la "negritud" del candombe. Por el contrario, cuando lo racial se materializa en determinados rasgos corporales y la "mezcla" se torna visible, las y los practicantes se filian al candombe exponiendo situaciones de racismo y discriminación vividas por ellos mismos y/o familiares y constatan la circulación cotidiana de categorías raciales y modos de vivir la negritud que son propios a nuestro contexto nacional. De esta manera, la inquietud por la filiación con el candombe afrouruguayo interroga el pasado familiar, la propia procedencia étnica y los imaginarios racializados, todo lo cual despierta dudas y/o sospechas sobre "quien se mezcló con quien" en las propias genealogías.

Estas situaciones permiten considerar que "no todo se piensa en términos de cultura cuando estamos en el campo de la diferencia" (WADE, 2014, p.51) y Argentina no es una excepción en el marco latinoamericano. Asimismo de ellas se desprende la discusión sobre la definición de los "cuerpos legítimos" (CAGGIANO, 2007) como uno de los recursos de constitución de lo nacional, lo que en este caso se expresa en el lugar que tiene la visibilidad/invisibilidad de ciertos rasgos corporales entre practicantes. A continuación, etnografio distintas respuestas a la inquietud por la filiación con el candombe y cómo 
interrogan el imaginario de un país libre de mestizaje y racismo (FRIGERIO, 2006).

\section{"Pero vos no sos negra": interpelaciones étnico-raciales}

Cuando no hay un rasgo corporal racializado/racializable, algunas/os practicantes movilizan otras explicaciones mediante las cuales identificarse con la negritud del candombe. Camila, una practicante de Paraná, describe un episodio vivido en el transporte público, mientras se trasladaba con tambores de candombe. Reproduce el inicio de una conversación con una pasajera, quien al verla con estos instrumentos la interpeló:

"Mujer: Pero vos no sos negra...

Practicante: No se... (Se ríe). Y no... (Agrega como describiendo algo evidente, pues su piel es muy clara) Tengo un apellido alemán. Pero en realidad mis ancestros entraron por Brasil" (Camila, practicante, Paraná, 10/12).

A partir de esta interpelación Camila reflexiona sobre su "búsqueda" por conocer "nuestras raíces". Según su lectura "vivimos en una historia que nos contaron, que sólo fue la europea" lo que provocó el desconocimiento de los "años que tuvimos de esclavitud negra" y el "acallamiento de los pueblos originarios". Para ella la "llegada del candombe" fue un disparador para cuestionar estas versiones de nuestra historia y preguntarse por su historia familiar. Así conversó con una abuela paterna que le transmitió que su tatarabuelo "se casó con una brasilera" y migró "desde Brasil". Esta historia abrió preguntas y sospechas que enumera de este modo: "¿porque me muevo así?, ¿porque me gusta bailar?, ¿porque me atrae tanto esta música?". De esta manera, Camila sugiere que su atracción por los tambores se deriva del emparejamiento sexual de su tatarabuelo con "una brasilera" -que supone "negra" - y apela a una genética que sin ser "visible", la habría aproximado al candombe (Camila, practicante, Paraná, 10/12). Como ya sugerimos, las representaciones exotizantes de la negritud afrodescendiente están presentes entre practicantes locales y suelen ser las menos problematizadas. En investigaciones previas registramos modos de representar a las manifestaciones afroamericanas que las concebían como algo "totalmente diferente" a lo actual, a lo que se vive en el cotidiano, lo cual en general asociaban a lo "pre-moderno", al "origen", a lo "verdadero", lo "puro", lo "incontaminado", a aquello que abriría vías de escape para encontrar otras 
formas de vida, de vínculos y de sociabilidad en el contexto local (BROGUET, CORVALÁN y RODRÍGUEZ, 2021). En este sentido, Frigerio (2005, p.99) indica que esta atracción por la diferencia "comparte con la estigmatización y el racismo el hecho de estar basado en un estereotipo que caricaturiza, homogeiniza y confirma una distancia con el individuo exotizado". Ademas de la tropicalidad que se asocia a Brasil (LINS RIBEIRO) uno de los componentes más frecuentemente asignados a este país en la Argentina es la negritud (FRIGERIO, 2005). Lo que en un contexto nacional considerado "blanco" hace que "los trazos culturales y fenotípicos negros brasileros constituy[an] un Otro lo suficientemente lejano como para generar atracción" (FRIGERIO, 2005, p. 115), todo lo cual emerge en el relato de Camila sobre su antepasada y la relación de necesariedad que plantea entre su origen étnico-racial y la cercanía con determinadas prácticas culturales como el tambor y el baile.

Dante, integrante de otra agrupación paranaense, subraya que pese al origen español de su apellido, necesita identificarse con "algo más propio, no tan ajeno" y afirma tener "mucho más de los pueblos originarios, de los pueblos afro, que de los pueblos europeos" (Dante, practicante, Paraná, 10/14). Luego sugiere que esta procedencia étnica debería corresponderse con su apariencia física. Sin embargo, acentúa que "no tiene el color". Al reconocer esta condición como un faltante, no apela a la visibilidad de este rasgo corporal para explicar su filiación con el candombe. Pero tampoco recurre -como sí lo hizo Camila- a la invisibilidad de la "sangre". Sino que señala que su identificación con la negritud es "política", pues se trata de "elegir cómo vivir" y a "quien recordar". Por eso revela que su acercamiento al "tema afro" le llega "investigando el problema de la propiedad de la tierra en Entre Ríos". Así relaciona su identificación con "los negros" a vivencias familiares propias, asociadas a episodios de "expulsión" e "invisibilización" de las poblaciones rurales pobres de Entre Ríos. Así admite que, aunque el "no vivió en el campo", si lo hicieron las generaciones que lo preceden, por lo cual "viene de una familia de campesinos expulsados". Por todo esto, el "elige" identificarse con procedencias étnicas prácticamente "censuradas" por el relato nacional $\operatorname{argentino~}^{22}$. En el próximo apartado ahondamos en los relatos de practicantes entre quienes la pregunta por la filiación con el candombe se articula a

\footnotetext{
${ }^{22}$ En su relato este practicante señaló repetidas veces que creció en una localidad entrerriana con presencia afrodescendiente producto de procesos migratorios originados por la huida de personas esclavizadas desde los estados brasileros de Rio Grande do Sul y Santa Catarina durante el siglo XIX (RICHARD Y LLALLAMI, 2017).
} 
señalamientos de rasgos corporales racializados, sobre todo el color "oscuro" de la piel.

\section{"Y descubri esa cosa del color": señalamientos de la "oscuridad" en la piel}

Aquí introducimos los señalamientos que realizan algunas/os practicantes en torno a la "oscuridad" de su piel, para en el próximo apartado profundizar este aspecto a partir de un relato en particular. Quienes mediante su acercamiento a una manifestación racializada señalan el estigma hacia el color "oscuro" de la piel en el contexto argentino, exteriorizan sus vivencias de discriminación en diferentes ámbitos -como la escuela o el espacio doméstico- y cuestionan situaciones durante años naturalizadas, que responden a un racismo de costumbre, no explicitado, irreflexivo y culturalmente establecido (SEGATO, 2006).

Algunas de las situaciones intrafamiliares refieren a distinciones por color de piel que los llevó a descubrir tempranamente "esa cosa del color" (Fernanda, practicante, Ibarlucea, 10/13). Es decir que el "color" no fue un rasgo con el cual se identificaron por iniciativa propia. Sino que por lo general fueron otros quienes se lo señalaron y no siempre de manera "cariñosa". Así, una practicante rosarina describía situaciones vividas en el espacio doméstico que buscaban atenuar la carga despectiva asociada a una mayor oscuridad en la piel: “ah... [Imitando la aclaración de otra persona] pero vos no sos negrita, vos sos... (Se ríe) trigueña ${ }^{23 "}$ (Marisa, practicante, Rosario, 04/16). Otras aludieron a situaciones similares, en las cuales algún rasgo físico más asociado a un fenotipo "blanco", mitigaba la oscuridad de la piel -observaciones como "es oscurita, pero al menos tiene ojos verdes" (Registro de observación, Rosario, 2017)-. O bien, indicaban que el color de piel era señalado en un tono acusatorio -“que oscurita que es, ese color es de la mamá" (Registro de observación, Rosario, 2017)-, por algún familiar de la línea paterna (o viceversa) que de ese modo expurgaba la negritud de su propia genealogía. En síntesis, estos comentarios son parte de tramas cotidianas permeadas por una percepción que hace del color de piel "oscuro" una marca generalmente negativa que es necesario matizar ("trigueña" y no "negrita"), compensar con otro rasgo favorable ("oscurita" pero de "ojos verdes") o expulsar del propio linaje (el color se hereda por una línea de parientes que no es la propia).

${ }^{23}$ Trigueña, es decir, del color del trigo. Se trata de una categoría del siglo XIX que permitió a algunas personas eludir el preconcepto de raza y el estigma asociado al color oscuro de la piel (ANDREWS, 1989). 
Además, observamos que la apariencia física puede incidir en los modos en que cada practicante elabora su vínculo con el candombe. En una conversación, Marisa relató que junto a su hermana pertenecen a una agrupación rosarina y aunque ambas reconocen su afrodescendencia, Marisa no tiene rasgos corporales que la evidencien, como sí le sucede a su hermana quien tiene piel oscura, labios gruesos y cabello ensortijado. Así describe que al estar haciendo candombe afrouruguayo en una agrupación rosarina, hay quienes creen que no es argentina ${ }^{24}$. Marisa observa que a su hermana "la debe haber marcado esto de ser negra", en alusión a la visibilidad de una marca corporal asociada a la afrodescendencia. Así, cuenta que su hermana:

Dice que se dio cuenta que era negra cuando una vez uno en la primaria le dijo "Ey, pero vos sos negra" (...) Es parecida a mi mamá por los rulos, mi vieja tiene rulos, pero se los plancha, así está todo el día planchándose los rulos, siempre la ves lacia, lacia (risas). Ves fotos de hermanos de mi abuelo que tienen rasgos muy afro. Pero siempre como que mi hermana era más negrita que nosotros por así decir (Marisa, practicante, Rosario, 04/16. Subrayado propio).

En este apartado adelantamos relatos de practicantes que señalan la "oscuridad" de la piel como un rasgo observado por personas externas en general de manera negativa. Al señalarlo/señalarse rebasan el ámbito de la experiencia personal para incluirse en un discurso de lo público. Este interés por hacer del prejuicio racial y las prácticas discriminatorias un tema para interrogarse y discutir junto a otras/os, no sólo objeta la versión de que en Argentina "no hay negros" ni "racismo", sino que resulta significativo si tenemos en cuenta cómo se "ocluye" esta dimensión a través de otros lenguajes que nombran la desigualdad, como el de clase social (FRIGERIO, 2006).

\section{La abuela "del interior": dimensiones de clase, étnico-raciales y de género en los relatos familiares}

En este último apartado ahondamos en el relato Fernanda, practicante de Paraná, a fin de exponer con más detalle los replanteos identitarios entre practicantes locales. En el relato de Fernanda -y en otros similares- el uso del

\footnotetext{
${ }^{24}$ Diferentes investigaciones han registrado cómo aquellas/os "afrodescendientes argentinos que, según las pautas locales, serían de 'raza negra'" son cotidianamente tratados como extranjeros (GELER, 2016, p. 74).
} 
término "negro/a" es ambivalente. Siguiendo a Bhabha (2002) en su observación sobre la "ambivalencia" del estereotipo colonial, entendemos que tal característica es la que permite que diferentes practicantes reúnan en una misma denominación experiencias que pueden aludir a un padecimiento, pero también a un orgullo referido a la negritud y transformar lo que inicialmente aparecía como un agravio, en un elemento de identificación. En sus relatos advertimos que por su carga histórica y moral, el término "negro/a" parece ser el más efectivo para interrogar la blanquitud y el europeísmo argentino.

Fernanda, a quien su entorno conoce como "La Negra", es de la ciudad de Paraná, hoy tiene alrededor de 40 años y trabaja como docente de danza. Al recordar sus comienzos menciona que "cuando apareció el candombe afrouruguayo [en Paraná] estaba toda esa cosa de la negritud" (Fernanda, practicante, Ibarlucea, 10/13). Según su relato, la inquietud por la filiación con el candombe se instaló hacia inicios del 2000 cuando circularon rumores en torno a la presencia "oculta" de población africana y afrodescendiente en la ciudad. De estas inquietudes surgió la idea de organizar un "Contrafestejo"25, una celebración callejera que desde el año 2002 se hace en el mes de octubre en la ciudad y recupera la memoria del antiguo barrio "del Tambor" 26. Durante la semana del Contrafestejo se hacen actividades en torno a temáticas históricas, reivindicaciones étnicas, ambientales, de género que ayudaron al fortalecimiento de una "conciencia crítica" (MATO, 2002, p.28) entre sus participantes. Quienes integran la agrupación local, tempranamente comenzaron a interesarse por los vínculos que esa historia podía tener con sus propias trayectorias personales/familiares:

El Contrafestejo, el museo, la charla de los túneles ${ }^{27}$, todas esas cosas, nos fueron generando [imitando a una tercera persona]: "ustedes pregunten, porque vemos muchos rasgos mezclados si nos miramos entre nosotros. Ustedes

\footnotetext{
${ }^{25}$ La iniciativa de los "contrafestejos" fue impulsada por organizaciones de pueblos indígenas y, en menor medida, del movimiento negro en 1992, a lo largo de toda América en ocasión de los 500 años de la denominada "Conquista o Descubrimiento de América".

${ }^{26}$ Desde comienzos del siglo XIX el barrio "del Tambor" era una zona de la ciudad poblada por africanos y afrodescendientes $\mathrm{y}$, al menos hasta comienzos del siglo $\mathrm{XX}$, seguía siendo reconocido por la presencia de "negros" (BROGUET, 2020).

27 Esta practicante se refiere al trabajo de investigación del Museo de Ciencias Naturales y Antropológicas "Prof. Antonio Serrano" y a los rumores que circularon en ese periodo sobre la presencia de restos óseos asociados a población africana/afrodescendiente en "túneles de Paraná". Estas versiones pretendían explicar la "desaparición" física de esta población en la ciudad colocando como escenario una red de túneles adjudicados a los jesuitas y que finalmente se identificaron como parte de una red de desagüe hechos en la segunda mitad del siglo XIX.
} 
pregunten en sus familias de donde vienen las raíces (Fernanda, practicante, Ibarlucea, 10/13. Subrayado propio).

Fernanda explica que en su hogar "jamás nadie la identificó como "negra'”. Incluso agrega que "a su papá que es medio morochito como ella, nunca le dijeron "negro'". Así subraya que en ese ámbito "nunca se identificó por su color, y menos como un insulto". Es durante su escolaridad primaria en Paraná donde inscribe "su primer encuentro con el color", tras situaciones en las que sus pares comienzan a designarla por su tono de piel y "recibe insultos" y tiene "peleas" por tal motivo. Asistió a una reconocida escuela pública de Paraná a la cual, según describe, asistía "gente de clase alta" y "bastante careta". "Careta" es un término coloquial que en nuestro país designa a alguien o a algo que aparenta ser algo que no es y, sobre todo, se emplea para referirse a personas que fingen una condición social que no tiene base material real. Tras hacer esta caracterización, Fernanda aclara que su familia "nunca fue de la clase alta" y manifiesta su resistencia a "caretear" una posición social que pudiera aparentar un estatus socio-económico diferente al que tenían. Durante su etapa escolar Fernanda se ubica como una persona que "tenía problemas", "bastante tímida" y "looser ${ }^{28 "}$. De ese modo, describe situaciones vividas durante la infancia que la hicieron "sufrir bastante". Así evoca el tono bromista de sus compañeras/os al momento de designarla con apodos peyorativos como "Chupetín de bleque" o "negra torta negra"29 y relata que "volvía a su casa llorando" para contarle a su mamá que en la escuela "le habían dicho negra":

Yo lloraba, porque era re maricona, y mi vieja me acuerdo que me decía: "Vos, cuando te digan eso, decíles: "Negra y a mucha honra". Que yo repitiera eso. Yo ni idea de lo que quería decir la palabra honra, pero lo repetía (Se ríe) (Fernanda, practicante, Ibarlucea, 10/13).

A comienzos del 2000, Fernanda rememora que junto a sus compañeras/os de candombe se instala una conciencia muy fuerte respecto al "gran genocidio" y "matanza" de pueblos indígenas y afrodescendientes en el continente y reconoce que el tema generó inquietudes de distinto orden. Así, recuerda los

\footnotetext{
${ }^{28}$ En inglés, perdedora.

${ }^{29}$ El bleque es una sustancia negra no comestible similar al alquitrán y un "chupetín" es una golosina esférica sostenida por un palito -en portugués sería equivalente al pirulito-. La "torta negra" es un producto panificado, de forma circular, que lleva azúcar negro como cobertura. En ambos casos son expresiones que establecen una similitud entre el rostro oscuro de una persona y la forma y color de los elementos escogidos: el chupetín y la torta.
} 
interrogantes compartidos con sus pares en torno la huella de estos acontecimientos en las memorias familiares y recupera las preguntas que se hacían: “¿no vamos a hacer nada al respecto? ¿Esto nunca se va a hablar?" evocando cómo en esos años se mencionaba mucho el término "visibilizar": "visibilizar la historia, visibilicemos, hablemos y recuperémoslo en la memoria".

Esta situación la llevó, como a otras/os compañeras/os, a indagar en su historia familiar. Como dijimos, Fernanda reconoce que su papá es "morochón", y que ella físicamente "es como él", e indica que su abuela paterna era "un poco más morocha" y "con unos rasgos más mestizos" pero que, en síntesis, "era muy parecida a ella", a quien en más de una oportunidad sus compañeras/os de candombe le adjudicaron una afrodescendencia. Como esta abuela paterna "murió cuando ella era chica", se acerca a su abuela materna con quien mantiene la primera conversación sobre el tema. Por su abuela supo que parte de su familia migró desde la provincia de Corrientes ${ }^{30}$ "en la frontera con Brasil" y que su tatarabuela "era aborigen y tenía el pelo negro hasta por acá (señalando con su mano)"31. Adjudica la escasa información sobre su antepasada al secretismo y silencio que rodeaba su figura y reproduce un dialogo en el cual subraya cómo su abuela le señaló repetidas veces que "de eso no se hablaba" en su familia:

Abuela: Era secreto, en mi familia de eso no se hablaba.

Fernanda: ¿Pero vos no sabes de que tribu era ella?

Abuela: No. Porque de eso no se hablaba.

Fernanda: Bueno, ¿pero más o menos vos no averiguaste de donde ella venía? ¿De qué zona?

Abuela: (Interrumpiendo) Yo lo único que sé, es que venía de la Cuchilla de Montiel, y no me preguntes más (Fernanda, practicante, Ibarlucea, 10/13).

$\mathrm{Al}$ volver a estos relatos familiares Fernanda advierte que como argentinos experimentamos "discontinuidades" con relación a generaciones previas y observa que "no partimos de nuestros abuelos, y nuestros abuelos de sus

\footnotetext{
${ }^{30}$ Corrientes es una provincia del noreste argentino.

${ }^{31}$ Fernanda menciona que su abuela sostiene un "mito" referido a que esta antepasada "era hija de un cacique". Ella señala cierto mecanismo de compensación en este "mito", según el cual el desprestigio representado por el origen indígena se subsanaría con una mayor "jerarquía" social. Según lo interpreta Fernanda, en el contexto en el cual creció su abuela -entre las décadas del 30 y del 40- resultaba crucial construir y preservar el estatus social. Por eso indica, irónicamente, que "tal vez la abuela era aborigen, pero era hija de un cacique".
} 
abuelos", sino que "hay una ruptura" en el medio. Así expone el retaceo de memorias vinculadas con procedencias étnico-raciales estigmatizadas y señala la posición de desventaja respecto a memorias de los orígenes familiares europeos idealmente más próximos a la composición de una Argentina "blanca" y que, en su caso, se vinculan al origen vasco derivado de su apellido paterno, el único conocido antes de escuchar los relatos referidos a la ascendencia indígena por línea materna y paterna.

Para describir cómo fue nombrada por otras personas y cómo ella misma se identifica, durante nuestra conversación Fernanda recurrió a tres términos referidos a un corrimiento de la blanquitud: "morocha", "morena" y "negra". En nuestro contexto nacional el primero funciona como una categoría racial/social, que excede lo concerniente a una afrodescendencia, pudiendo designar a cualquier argentino/a no lo suficientemente blanco e incluso emplearse con relativa independencia del fenotipo de una persona. En el caso de "morocha/o", se trata de un término local con varios usos en Argentina y a diferencia de negra/o no suele aludir a una condición social. Es corriente que se emplee para hablar de una persona de pelo negro y tez oscura. Aunque a veces puede referir a otros rasgos de la apariencia corporal, como el color de pelo, sin que vaya acompañado por una piel amarronada. Ocasionalmente, también puede emplearse para designar a una persona afrodescendiente en su presencia, buscando reducir la carga peyorativa asociada al término negro/a. En el caso de las mujeres, el término "morocha" puede adquirir una mayor connotación sexual respecto a los varones, pues aparece asociado a un cuerpo "con curvas" (caderas grandes y pechos abultados) y a ciertas características de personalidad (fortaleza o seguridad), en consonancia con estudios que analizan la sexualización de la raza en otros contextos latinoamericanos (WADE, URREA GIRALDO y VIVEROS VIGOYA, 2008). De allí que, como expresamos algunos párrafos más arriba, Fernanda apela al diminutivo lo cual atenúa la carga sexuada asociada al término, y no se designa "morocha" sino "morochita". Finalmente, "morena" no es un término muy frecuente en nuestro país. Aquí aparece como un mote que en algunas oportunidades le otorgaron sus pares por la cercanía con el candombe afrouruguayo, contexto en el cual está denominación es más frecuente y suele aludir a la ascendencia africana de una persona. En este caso, a Fernanda el término "morochita" le permite indicar rasgos corporales racializados -sin por eso hacer referencias a una pertenencia étnica-. Mientras que el término "morena" le resulta algo ajeno, pues es contundente al enfatizar su "plena conciencia" de que en Argentina "somos una mezcla" y "no venimos solo de la comunidad africana". 
Para ir cerrando este relato, Fernanda actualmente se nombra a sí misma y acepta ser nombrada como "La Negra". Si bien en su infancia tal denominación resultó estigmatizante, hoy le permite recuperar los componentes omitidos de esa "mezcla" que conformó su historia familiar. El término "negra" admite invertir el uso acusatorio que de él hicieron sus pares en el ámbito escolar al señalarle negativamente su color de piel tanto como recurrir a los usos reivindicatorios de la negritud surgidos en el contexto argentino de las últimas décadas (LAMBORGHINI y GELER, 2017) ${ }^{32}$. Finalmente, la ambigüedad del término "negra" habilita a que Fernanda pueda subrayar la presencia indígena como un componente ineludible de esa "negritud argentina" y, al mismo tiempo, no descarte del todo la posibilidad de una ascendencia africana por parte de esa abuela paterna "morocha" con la que más se identifica físicamente.

\section{Palabras de cierre}

Para acercarnos a los replanteos identitarios que generó el encuentro con el candombe afrouruguayo entre practicantes argentinas/os comencé describiendo cómo éstos se desenvuelven en dinámicas de mestizaje y blanqueamiento que se distribuyen a lo largo de un territorio nacional segmentado étnico-racialmente (BRIONES, 2005). A partir de allí puntualizamos cómo hacer candombe involucra experiencias corporales y afectivas asociadas a lo comunitario y produce inquietudes en torno a la "filiación", detallando de este modo procesos locales derivados de su práctica. En este punto, observamos que la blanquitud imaginada para Argentina, reguló las apariencias corporales y las maneras de percibirlas/valorarlas (CAGGIANO, 2007) detallando el papel que tiene la visibilidad/invisibilidad de ciertos rasgos corporales (color de piel, tipo de pelo, rasgos faciales) en la inquietud por la "filiación" con el candombe. A fin de profundizar en las dimensiones étnico-raciales involucradas en los replanteos identitarios analizados, ahondé en el relato familiar de una practicante. Allí describí cómo estos replanteos envolvieron una nueva mirada de las propias corporalidades y busqué exponer cómo la ideología racial implícita en la narrativa nacional se vive como una experiencia encarnada.

\footnotetext{
32 Diferentes investigaciones locales registran la circulación de formas reivindicativas de la negritud -en un sentido amplio, que no se refiere solo a la afrodescendencia- (LAMBORGHINI y GELER, 2017).
} 
El interés con este recorrido fue interrogar a un sector mayoritario de la sociedad nacional que logra/puede incluirse en la blanquitud/argentinidad. Las agrupaciones de candombe con las que trabajé fueron espacios que alojaron las retrospectivas familiares emprendidas por algunas/os de sus integrantes. De este modo, el contacto con una práctica racializada colaboró con el reconocimiento de procesos distintivos del contexto nacional, permitiéndoles interrogar la narrativa de blanqueamiento como condición excluyente para pertenecer a la nación/familia argentina y exponer los conflictos irresueltos que tal construcción aloja.

Los usos de la negritud entre practicantes más que a una reivindicación exclusiva de la afrodescendencia aluden a aquellos cuerpos que en Argentina son racializados como "negros", particularmente por su color de piel oscuro. De allí que destacan la "mezcla" del componente europeo, indígena y afrodescendiente como el objeto privilegiado del prejuicio racial en el contexto nacional. Sin escapar a una lógica racializada pero contrariamente a la aspiración homogeneizante que subyace al mestizaje como ideología nacional (VIVEROS VIGOYA, 2000), mediante estas imágenes asociadas a la "mezcla/mistura/cruza" las y los practicantes recalcan la heterogeneidad constitutiva de la sociedad local.

Así, los interrogantes que plantea el candombe afrouruguayo a sus practicantes locales friccionan el sentido común de la normalidad argentina a nivel de las tramas familiares ${ }^{33}$. El encuentro con el candombe re-situó a las y los practicantes como sujetos de una historia que ya no es "la de otros" sino la "propia" y los convocó a indagar en relatos que, en favor de ajustarse a la representación de una argentinidad compuesta exclusivamente por colectividades migrantes europeas, fueron hasta no hace mucho tiempo (y en muchos casos siguen siendo) persistentemente marginados de sus memorias familiares pero también, y en general, de la historia en común con la que se identifican al reconocerse "argentinos/as".

\footnotetext{
${ }^{33}$ Utilizamos la expresión "normalidad argentina" en el sentido de elegir arbitrariamente una identidad específica como el parámetro con relación al cual las otras identidades solo pueden ser evaluadas de forma negativa (HALL, 2003).
} 


\section{Bibliografía}

ANDREWS, George

(1989 [1980]). Los afroargentinos de Buenos Aires. Buenos Aires: Ediciones de la Flor.

(2007) Recordando África al inventar Uruguay: Sociedades de negros en el Carnaval de Montevideo, 1865-1930. Revista de Estudios Sociales, 26, pp. 86-104.

BRIONES, Claudia

(2005). Mestizaje y blanqueamiento como coordenadas de aboriginalidad y nación en Argentina, Runa XXIII, pp. 61-88.

(2008). (comp.) Cartografias Argentinas. Buenos Aires: Antropofagia

BROGUET, Julia

(2012). -Saberes incorporados- Apropiaciones y resignificaciones de las danzas religiosas de orixás en un ámbito artístico. Tesis de licenciatura 'resentada en la UNR, Rosario.

(2018). Candombe afrouruguayo, color de piel y blanquitud en el Litoral argentino. En Revista Claroscuro, Año 17, Vol. 17, pp. 1-27.

(2020). "Salir de la blanquitud": candombe afrouruguayo y categorías étnico-raciales en Paraná, Santa Fe y Rosario (fines del siglo XX2015). Tesis de doctorado presentada en la UBA, Buenos Aires, Argentina.

(2021). El "Centro" y los "barrios" Candombe afrouruguayo, límites sociales y étnico-raciales en el espacio urbano de Paraná y Santa Fe (Argentina). En Cuadernos de Antropología Social/54, pp. 115-132.

BROGUET, Julia, CORVALÁN, Ma. Laura y RODRÍGUEZ, Manuela

(2021). Prácticas artísticas de matriz africana en Rosario: performatividades 'negras' en contextos 'blancos'. en: Catelli, L., LepeCarrión, P.y Rodríguez M. (Comp) Condición (pos)colonial y racialización. Mendoza, Argentina: Editorial Qellqasqa, pp. 159-199.
BROGUET, Julia, RODGRÍGUEZ, Manuela y PICECH, Ma. Cecilia

(2014) "Argentina tiene un gran problema de identidad...": Resignificando lo propio y lo ajeno del candombe en el Litoral argentino". En Cristina Di Bennardis (comp.) Experiencias de la diversidad, Rosario: UNR Editora, pp 350 364.

CAGGIAN0, Sergio

(2015). Imaginarios racializados y clasificación social: retos para el análisis cultural (y pistas para evitar una deriva decolonial esencialista). Cuadernos Intercambio sobre Centroamérica y el Caribe. Vol. 12, No. 2, pp.159-190.

\section{CORTI, Berenice}

(2010). Discursos de raza y nación en y sobre Sarmiento. La (im)posibilidad mestiza de la "blanquedad" porteña. En Actas de las I Jornadas de Estudios Afrolatinoamericanos del GEALA.

CUNIN, Elisabeth

(2010). (dir.) Mestizaje, diferencia y nación: Lo "negro" en América Centraly el Caribe. México: Centro de estudios mexicanos y centroamericanos

FERNANDEZ BRAVO, Nicolás

(2014). El regreso del cabecita negra. Ruralidad, desplazamiento y reemergencia identitaria entre los santiagueños "afro". Actas del XI Congreso Argentino de Antropología Social, Rosario.

\section{FERREIRA, Luis}

(1999a). 'Negros-Viejos' y 'Guerreros Africanos' en 'los tambores' afro-uruguayos: un caso de liminaridad entre performance musical y religión. En Actas IX Jornadas sobre alternativas religiosas na America Latina.

(1999b). Las llamadas de tambores. Comunidade identidad de los afro-montevideanos. Tesis de maestría presentada en la UNB, Brasilia. 
FRIGERI0, Alejandro

(2000). Cultura negra en el cono sur. Representaciones en conflicto. Ed. de la U.C.A., Bs. As.

(2005). Migrantes exóticos: Los brasileros en Buenos Aires. Runa, núm. XXV, 2005, pp. 97121

(2006). "Negros" y "blancos" en Buenos Aires: repensando nuestras categorías raciales. Temas de Patrimonio Cultural 16, pp. 77-98.

FRIGERI0, Alejandro y LAMBORGHINI, Eva

(2012). Encontrarse, compartir, resistir: Una "nueva construcción" del candombe (afro)uruguayo en Buenos Aires. Anuario de Antropología Social y Cultural en Uruguay, Vol. 10, pp.95-113.

GELER, Lea

(2011) ¿Quién no ha sido negro en su vida? Performances de negritud en el carnaval porteño de fin de siglo (xix-xx). En: Pilar García Jordán El Estado en Aca. Latina: recursos e imaginarios (pp. 183-211). Barcelona: Publicacions i Edicions de la Universitat de Barcelona.

(2016). Categorías raciales en Buenos Aires. Negritud, blanquitud, afrodescendencia y mestizaje en la blanca ciudad capital. Runa vol. $37 \mathrm{n}^{\circ} 1$, pp 71-87.

HALL, Stuart

(2003). Cuestiones de identidad cultural. Buenos Aires: Amorrortu Editores.

LAMBORGHINI, Eva y GELER, Lea

(2016). Introducción al debate: Imágenes racializadas: políticas de representación y economía visual en torno a lo "negro" en Argentina, siglos XX y XXI. Revista Corpus. Archivos virtuales de la alteridad americana. Vol. $6, \mathrm{n}^{\circ} 2$.

LAMBORGHINI, Eva, GELER, Lea y GUZMAN, Florencia

(2017). Los estudios afrodescendientes en argentina: nuevas perspectivas y desafíos en un país «sin razas». En Tabula Rasa. No.27, pp.67101.
LINS RIBEIR0, Gustavo

(2002). Tropicalismo e Europeísmo. Modos de representar o Brasil e a Argentina. En Alejandro Frigerio y Gustavo Lins Ribeiro (comps) Argentinos e brasileños. Encontros, imagens e estereotipos, Petrópolis, Vozes, pp.237-264.

MATO, Daniel

(2002). Estudios y otras prácticas intelectuales latinoamericanas en cultura y poder. En: Estudios y Otras Prácticas Intelectuales Latinoamericanas en Cultura y Poder. Caracas: CLACSO/CEAP/FACES/UCV.

\section{MORENO FIGUEROA, Mónica}

(2010). Mestizaje, cotidianeidad y las prácticas contemporáneas del racismo en México. En Elizabeth Cunin (dir.) Mestizaje, diferencia y nación: Lo "negro" en América Central y el Caribe. México: Centro de estudios mexicanos y centroamericanos

NARI, Marcela

(1999). La eugenesia en Argentina, 1890-1940. Quipu, vol. 12, n³, pp. 343-369.

\section{RAHIER, Jean}

(1999). 'Mami, ¿qué será lo que quiere el negro?': representaciones racistas en la revista Vistazo, 1957-199". En Emma Cervone y Fredy Rivera Ecuador racista, Quito: Flacso Ecuador, pp. 73110.

\section{RICHARD, Alejandro y LALLAMI, Cristian}

(2017). Afrodescendientes en Entre Ríos. Oralidad y arqueología histórica en torno al caso de Ingeniero Sajaroff, dpto. Villaguay Cuadernos del Instituto Nacional de Antropología y Pensamiento Latinoamericano 26 (1), pp. 21-41.

SEGATO, Rita

(2006). Racismo, discriminación y acciones afirmativas: herramientas conceptuales. Série antropologia $404, \mathrm{~s} / \mathrm{p}$.

\section{UNESCO}

(2009). El candombe y su espacio sociocultural: una práctica comunitaria, expediente $n^{\circ} 00182$. Disponible en: https://ich.unesco.org/es/RL/el-candombey-su-espacio-sociocultural-una-practicacomunitaria-00182 
VIVEROS VIGOYA, Mara

(2020). Dionisios negros Estereotipos sexuales y orden racial en Colombia. En Luis García Núñez, Mario Figueroa Muñoz y Pío San Miguel (eds.) ¿Mestizo yo? Bogotá: CES-UNAL, pp. 95-130.

WADE, Peter

(2014). Raza, ciencia, sociedad. Interdisciplina 2, n4, pp. 35-62.

(2013) Racismo, democracia racial, mestizaje y relaciones de sexo/género. En Tabula Rasa, $\mathrm{N}^{\circ} 18$, pp. 43-72.
WADE, Peter, URREA GIRALD0, Fernando y VIVEROS VIGOYA, Mara (eds)

(2008). Raza, etnicidad y sexualidades. Ciudadanía y multiculturalismo en América Latina Bogotá: UNAL.

\section{Recebido em}

julho de 2021

\section{Aprovado em}

novembro de 2021 